\title{
Wind Energy Generation Integrated to Grid System: Power Quality Issues
}

\author{
Dipesh Kumar Sharma ${ }^{1}$, Dr. S. P. Shukla ${ }^{2}$ \\ ${ }^{1,2}$ Department of Electrical Engineering, Bhilai Institute of Technology, Durg, Chhattisgarh, India
}

\begin{abstract}
It is known that integration of wind power to the Electrical Grid affects the power quality and hence affect the stability of the grid. In new of power quality the impact of wind turbine with grid integrated are active power, reactive power, change in voltage, Harmonics, flicker and electrical behavior of switching operation and there are measured according to the National/ International standards. This paper discussion the power quality problem due to installation of wind turbine with grid. The pulse with modulation $(P W M)$ inferior scheme for grid connected wind mill for power quality improvement is considered in this study.
\end{abstract}

Keywords: Pulse width modulation, power quality, stability, harmonics

\section{Introduction}

As the contribution of different generation sources to the grid was in team amount but how a days the contribution of other generating sources have increased in a considerable amount such the it can have impact on the behavior of the grid , Particularly the contribution of wind generation is sharing its grid amount of generation to the grid which will be having impact of electrical gird, As feeding into distribution network with high source impedance.

In general the power quality can be understand by the meaning that how closely the electrical power delivered to customer corresponding to the required standard so the equipment will function correctly. Now a day the importance of power quality issue has became so relevant as the usage of power electronics equipment has gone so high, no buddy will deny the importance of such as power electronic converter and programmable logic controller.

As due to nonlinear and sensitive in nature of these loads are majorly affected by the power quality problem at the very same time they are the major victim of power quality problem also will lead to disturbance in the waveform.

There are two types of turbines namely fixed speed and variable speed turbine, in fixed speed turbine variation in speed lend to large voltage fluctuating on grid where as in case of variable speed wind turbine where we use power electronic devices, in this can we require to take into consideration about harmonic distortion. In normal operation also due to turbulence wind shear and tower shadow, the wind turbine produces a continues variable output power.

\section{Impacts of Wind Farms on Power Quality}

There are certain issues which forces us to go for the analysis of power quality such as:

The lasted equipments in the power system are with microprocessor based control and power electronic devices, are more sensitive to power quality than used in past. To increase overall efficiency in the system, use of adjustable speed motor, power factor correction are result in increase of harmonics level in power system. Deregulation of utilities, distributed generations have increase the power quality problem .Awareness of end user for interruption, switching transients. Globalization of industry around the world.

The impact of wind power on Power Quality will be as below:

\section{A. Voltage Variations}

On the local level, voltage variations are the main problem associated with wind power. This can be the limiting factor on the amount of wind power which can be installed. In normal operational condition, the voltage quality of a wind turbine or a group of wind turbines may be assessed in terms of the following parameters [10]:

a) Steady state voltage under continuous production of power

b) Voltage fluctuations

- Flicker during operation

- Flicker due to switching

The influence of connecting a wind farm on the gird voltage is directly related to the short circuit power level. The short circuit power level in a given point in the electrical network represents the system strength. If the voltage at a remote point can be taken as constant, Us , and the short circuit power level SSC in MVA is defined as $\mathrm{Us}^{2} / \mathrm{Zk}$ where $\mathrm{Zk}$ is the equivalent impedance between the points concerned.

Fig. 3 illustrates an equivalent wind power generation unit, connected to a network with equivalent short circuit impedance, $Z_{k}$. The network voltage at the assumed infinite busbar and the voltage at the Point of Common Coupling (PCC) are $U_{s}$ and $U_{g}$, respectively. The output power and reactive power of the generation unit are $P_{g}$ and $Q_{g}$, which corresponds to a current $I_{g}$.

$$
I_{t}-\left(s_{\sharp} / U_{t}\right)=\frac{P_{z}-j Q_{z}}{U_{s}}
$$

The voltage difference, $U$, between the system and the connection point is given by 


\section{International Journal of Science and Research (IJSR) \\ ISSN (Online): 2319-7064}

Index Copernicus Value (2013): 6.14 | Impact Factor (2014): 5.611

$$
\begin{aligned}
& U_{\xi}-U_{k}=U=Z_{k} \quad I_{g}=\left(R_{k}+j X_{k}\right)\left(\frac{P_{g}-j \underline{Q}_{z}}{U_{t}}\right) \\
& =\frac{R_{i} P_{t}+X_{i} Q_{t}}{U}+j \frac{P_{z} X_{k}-Q_{z} R_{k}}{U}=U_{p}+j U_{q}
\end{aligned}
$$

The voltage difference, $U$, is related to the short circuit impedance, the real and reactive power output of the wind power generation unit. It is clear that the variations of the generated power will result in the variations of the voltage at PCC. If the impedance $\mathrm{Zk}$ is small then the voltage variations will be small (the grid is strong). On the other hand, if $\mathrm{Zk}$ is large, then the voltage variations will be large (the grid is weak). However, strong or weak are relative concepts. For a given wind power capacity $\mathrm{P}$ the ratio RSC $=\mathrm{SSC} / \mathrm{P}$ is a measure of the strength. The grid may be considered as strong with respect to the wind farm installation if RSC is above 20.

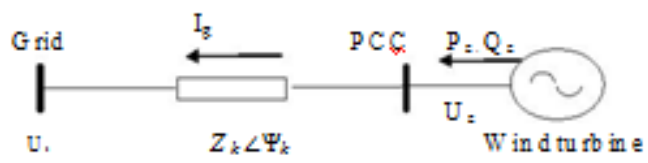

Figure 3: A simple system with an equivalent wind power generator connected to a network.

\section{B. Steady-state voltage}

Equation (2) indicates the relationship between the voltage and power transferred into the system. The voltage difference, $U$, can be calculated with load flow methods as well as other simulation techniques [11]. The voltage at PCC should be maintained within utility regulatory limits. Operation of wind turbines may affect the voltage in the connected network. If necessary, the appropriate methods should be taken to ensure that the wind turbine installation does not bring the magnitude of the voltage outside the required limits.

It is recommended that load-flow analyses be conducted to assess this effect to ensure that the wind turbine installation does not bring the magnitude of the voltage outside the required limits.

Depending on the scope of the load-flow analysis, a wind turbine installation may be assumed as a PQ node, which may use ten minutes average data $\left(P_{m c}\right.$ and $\left.Q_{m c}\right)$ or $60 \mathrm{~s}$ average data $\left(P_{60}\right.$ and $\left.Q_{60}\right)$ or $0.2 \mathrm{~s}$ average data $\left(P_{0.2}\right.$ and $\left.Q_{0.2}\right)$.

A wind farm with multiple wind turbines may be represented with its output power at the PCC. Ten minute average data $\left(P_{m c}\right.$ and $\left.Q_{m c}\right)$ and $60 \mathrm{~s}$ average data $\left(P_{60}\right.$ and $Q_{60}$ ) can be calculated by simple summation of the output from each wind turbine, whereas $0.2 \mathrm{~s}$ average data $\left(P_{0.2}\right.$ and

$Q_{0.2}$ ) may be calculated according to equations (3) and (4) below.

$$
\begin{aligned}
& P_{02 \Sigma}=\sum_{j=1}^{N_{2 N}} P_{N i}+\sqrt{\sum_{i=1}^{N}\left(P_{02 j}-P_{w j}\right)^{2}} \\
& Q_{0 x \Sigma}-\sum_{i=1}^{N_{N}} Q_{N,}+\sqrt{\sum_{i=1}^{N_{n}}\left(Q_{0, j}-Q_{N}\right)^{2}}
\end{aligned}
$$

where $P_{n, i}, Q_{n, i}$ are the rated real and reactive power of the individual wind turbine; $N_{w t}$ is the number of wind turbines in

the group.

\section{Voltage Fluctuations}

Fluctuations in the system voltage (more specifically in its rms value) may cause perceptible light flicker depending on the magnitude and frequency of the fluctuation. This type of disturbance is called voltage flicker, or shortened as flicker.

There are two types of flicker emissions associated with wind turbines, the flicker emission during continuous operation and the flicker emission due to generator and capacitor switchings. Often, one or the other will be predominant. The allowable flicker limits are generally established by individual utilities. Rapid variations in the power output from a wind turbine, such as generator switching and capacitor switching, can also result in variations in the RMS value of the voltage. At certain rate and magnitude, the variations cause flickering of the electric light. In order to prevent flicker emission from impairing the voltage quality, the operation of the generation units should not cause excessive voltage flicker.

IEC 61000-4-15 specifies a flickermeter which can be used to measure flicker directly [12]. The flicker measurement is based on the measurements of three instantaneous phase voltages and currents followed by using a "flicker algorithm" to calculate the Pst and Plt. where Pst is the short term flicker severity factor and measured over 10 minutes, and the long term flicker severity factor Plt is defined for two hour periods. The flicker assessments can also be conducted with simulation method [13].

Disturbances just visible are said to have a flicker severity factor of Pst $=1$ The flicker emissions, $P_{s t}$ and $P_{l t}$ may also be estimated with the coefficient and factors, $\mathrm{c}_{\mathrm{f}}\left(\Psi_{k}, v_{a}\right)$ and $k_{f}\left(\Psi_{k}\right)$ obtained from the

measurements, which are usually provided by wind turbine manufacturers.

The flicker emissions from a wind turbine installation should be limited to comply with the flicker emission limits. It is recommended [3] that $P_{l t} \leq 0.50$ in $10-20 \mathrm{kV}$ networks and $P_{l t} \leq 0.35$ in $50-60 \mathrm{kV}$ networks are considered acceptable. However, different utilities may have different flicker emission limits. The assessments of the flicker emissions are described below.

\section{1) Continuous Operation}

The flicker emission from a single wind turbine during continuous operation may be estimated by:

$$
P_{s t}=c_{f}\left(\psi_{k}, v_{a}\right) \frac{S_{n}}{S_{k}}
$$

Where $c_{f}\left(\Psi_{k}, v_{a}\right)$ is the flicker coefficient of the wind turbine for the given network impedance phase angle, $\Psi_{k}$, at the PCC, and for the given annual average wind speed, $v_{a}$, at the PCC, and for the given annual average wind speed, $v_{a}$, at hub-height of the wind turbine. 


\section{International Journal of Science and Research (IJSR) \\ ISSN (Online): 2319-7064}

Index Copernicus Value (2013): 6.14 | Impact Factor (2014): 5.611

A table of data produced from the measurements at a number of specified impedance angles and wind speeds can be provided by wind turbine manufactures. From the table, the flicker coefficient of the wind turbine for the actual $\Psi_{k}$ and $v_{a}$ at the site may be found by applying linear interpolation.

The flicker emission from a group of wind turbines connected to the PCC is estimated using equation (6)

$P_{s t \Sigma}=\frac{1}{S_{k}} \sqrt{\sum_{i=1}^{N}\left(c_{f, i}\left(\psi_{k}, v_{a}\right) S_{n, i}\right)^{2}}$

Where $c_{f, i}\left(\Psi_{k}, v_{a}\right)$ is the flicker coefficient of the individual wind turbine; $S_{n, i}$ is the rated apparent power of the individual wind turbine; $N_{w t}$ is the number of wind turbines connected tothe PCC.

If the limits of the flicker emission are known, the maximum allowable number of wind turbines for connection can be determined.

\section{2) Switching Operations}

The flicker emission due to switching operations of a single wind turbine can be calculated as

$$
P_{s t}=18 \times N_{10}^{0.31} \times k_{f}\left(\psi_{k}\right) \frac{S_{n}}{S_{k}}
$$

where $k_{f}\left(\Psi_{k}\right)$ is the flicker step factor of the wind turbine for the given $\Psi_{k}$ at the PCC.

The flicker step factor of the wind turbine for the actual $\Psi_{k}$ at the site may be found by applying linear interpolation to the table of data produced from the measurements by wind turbine manufacturers.

The flicker emission from a group of wind turbines connected to the PCC can be estimated from:

$$
P_{s t \Sigma}=\frac{18}{S_{k}}\left(\sum_{i=1}^{N_{k}} N_{10, i}\left(k_{f, i}\left(\psi_{k}\right) S_{n, i}\right)^{3.2}\right)^{0.31}
$$

Where $k_{f, I} \quad\left(\Psi_{k}\right)$ is the flicker step factor of the individual wind turbine; $\mathrm{N}_{10, \mathrm{i}}$ and $\mathrm{N}_{120, \mathrm{i}}$ are the number of switching operations of the individual wind turbine within 10 minute and 2 hour period respectively. $S_{n, i}$ is the rated apparent power of the individual wind turbine; Again, if the limits of the flicker emission are given, themaximum allowable number of switching operations in a specified period, or the maximum permissible flicker emission factor, or the required short circuit capacity at the PCC may be determined.

\section{Harmonics}

Harmonic disturbances are a phenomenon associated with the distortion of the fundamental sine wave and are produced by non-linearity of electrical equipment. Harmonics causes increased currents, power losses and possible destructive overheating in equipment. Harmonics may also rise problems in communication circuits. Harmonic standards are specified

to set up the limits on the Total Harmonic Distortion (THD) as well as on the individual harmonics.

Power electronic converters, which operation in an on-and- off way, are used in variable speed wind turbine systems $[14,15]$. The Pulse Width Modulation (PWM) switching frequency, with a typical switching frequency of a few thousand $\mathrm{Hz}$, shifts the harmonics to higher frequencies where the harmonics can be easily removed by smaller filters. In general harmonic standards can be met by modern wind turbines.

\section{Requirements of Connecting Wind Farm into Power Systems}

Integration of large scale wind power may have severe impacts on the power system operation. Traditionally, wind turbines are not required to participate in frequency and voltage control. However, in recent years, attention has been increased on wind farm performance in power systems. Consequently, some grid codes have been defined to specif the steady and dynamic requirements that wind turbines must meet in order to be connected to the grid. Examples on such requirements are capabilities of contributing to frequency and voltage control by continuous modulation of active power and reactive power supplied to the transmission system, as well as the power regulation rate that a wind farm must provide.

Some specifications have been worked out with regard to the preparations for future large offshore wind farms as the following example [3]. Active power and frequency control: the active power is regulated linearly with frequency variation between a certain range $(47 \mathrm{~Hz}-52 \mathrm{~Hz})$ with a dead band $(49.85 \mathrm{~Hz}-50.15 \mathrm{~Hz})$ and the regulating speed is $10 \%$ of the rated power per second, The reactive power should be regulated within a control band, at a maximum level of $10 \%$ of rated power (absorption at zero real power and production at the rated real power), $\bullet$ Wind turbine will generally operate in normal conditions $(90 \%-105 \%$ voltage and $49-51 \mathrm{~Hz}$ ), however, it should also be able to operate outside of the above conditions within certain specified time limits, $\bullet$ Under the condition of a power system fault, a wind turbine would experience a voltage variation. The severer degree of the voltage variation and the time period of such voltage variation will determine whether the wind turbine must not be disconnected (ride through) or may be disconnected or must be disconnected -Also the wind turbine has to be able to withstand more than one independent faults occurred in a few minute intervals.

There are also requirements related to rapid voltage variations, flickers, harmonics and interharmonics. A series of special test conditions have been set and the wind turbines have to meet these conditions accordingly before they can be connected into the power system. The regulation ability of reducing the wind turbine production from full load to a level between 0 and 20 per cent in a few seconds is required.

\section{Wind Farms Operation and Control, Stability Improvement}

A lot research has been conducted in answering the challenges [16-27]. In this section, some possible methods of dealing with the above requirements are discussed. 


\section{International Journal of Science and Research (IJSR) \\ ISSN (Online): 2319-7064}

Index Copernicus Value (2013): 6.14 | Impact Factor (2014): 5.611

\section{A. Frequency and power control}

The real power generation of a wind turbine can be regulated down but it may be difficult to increase the power output since the input power is limited by the wind speed. However, some spinning reserve may be kept if the wind turbine is operated at a lower power level than the available power level which means a reduction in generation, and hence reduced revenues.

Large scale energy storage system may present an answer, some fast response energy storage devices could be well technically suited for this purpose though more work is needed to make the solution an economic one [16]. From the system operatores point view, a system level hot reserve allocation amount the generation units may be more cost effective to deal with the problem if possible.

\section{B. Reactive power compensation}

Many wind turbines are equipped with induction generators which consume reactive power. At no load (idling), the reactive power consumption is about $35-40 \%$ of the rated active power, and increases to around $60 \%$ at rated power. Reactive power is one of the major causes of voltage instability in the network due to the associated voltage drops in the transmission lines, reactive current also contributes to system losses.

Locally installed capacitor banks may compensate the reactive power demand of the induction generators. For WT with self commutated power electronic systems, the reactive power can be controlled to minimize losses and to increase voltage stability. Thus these WT can have a power factor of 1.00 , as well as have the possibility to control voltage by controlling the reactive power. For a large scale wind farm, a central reactive power compensation device, such as SVC or STATCOM may be used to provide a smooth reactive power regulation [16].

\section{Stability Support}

An important issue when integrating large scale wind farms is the impacts on the system stability and transient behavior. System stability is largely associated with power system faults in a network such as tripping of transmission lines, loss of production capacity (generator unit failure) and short circuits. These failures disrupt the balance of power (active and reactive) and change the power flow. Though the capacity of the operating generators may be adequate, large voltage drops may occur suddenly. The unbalance and redistribution of real and reactive power in the network may force the voltage to vary beyond the boundary of stability. A period of low voltage (brownout) may occur and possibly be followed by a complete loss of power (blackout).

Many of power system faults are cleared by the relay protection of the transmission system either by disconnection or by disconnection and fast reclosure. In all the situations the result is a short period with low or no voltage followed by a period when the voltage returns. A wind farm nearby will see this event. In early days of the development of wind energy, only a few wind turbines were connected to the grid. In this situation, when a fault somewhere in the lines caused the voltage at the wind turbine to drop, the wind turbine was simply disconnected from the grid and was reconnected when the fault was cleared and the voltage returned to normal. Because the penetration of wind power in the early days was low, the sudden disconnection of a wind turbine or even a wind farm from the grid did not cause a significant impact on the stability of the power system. With the increasing penetration of wind energy, the contribution of power generated by a wind farm can be significant. If the entire wind farm is suddenly disconnected at full generation, the system will loss further production capability. Unless the remaining operating power plants have enough "spinning reserve", to replace the loss within very short time, a large frequency and voltage drop will occur and possibly followed by complete loss of power. Therefore, the new generation of wind turbines is required to be able to "ride through" during disturbances and faults to avoid total disconnection from the grid.

In order to keep system stability, it is necessary to ensure that the wind turbine restores normal operation in an appropriate way and within appropriate time. This could have different focuses in different types of wind turbine technologies, and may include supporting the system voltage with reactive power compensation devices, such as interface power electronics, SVC, STATCOM and keeping the generator at appropriate speed by regulating the power etc. [22-27].

\section{A Simulation Example}

The studied system is shown in Fig. 4 [27], where the load at bus 2 is supplied by the grid and the wind farm with wound rotor induction generators represented by a single machine at bus 3. The capacitor DC link for STATCOM is simplified as a constant dc voltage source. It is also assumed that the switching duty ratio of the power devices connected in the rotor circuit is kept constant during the dynamics.

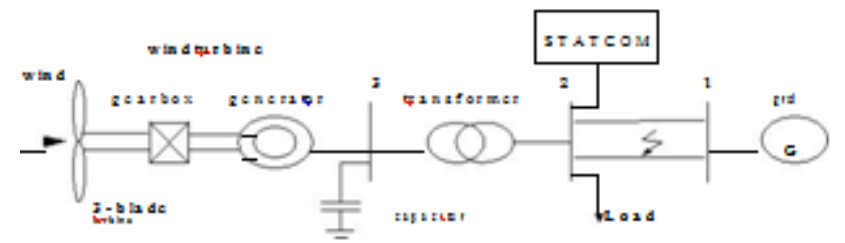

Fig. 4. Block diagram of a wind turbine connected to a grid.

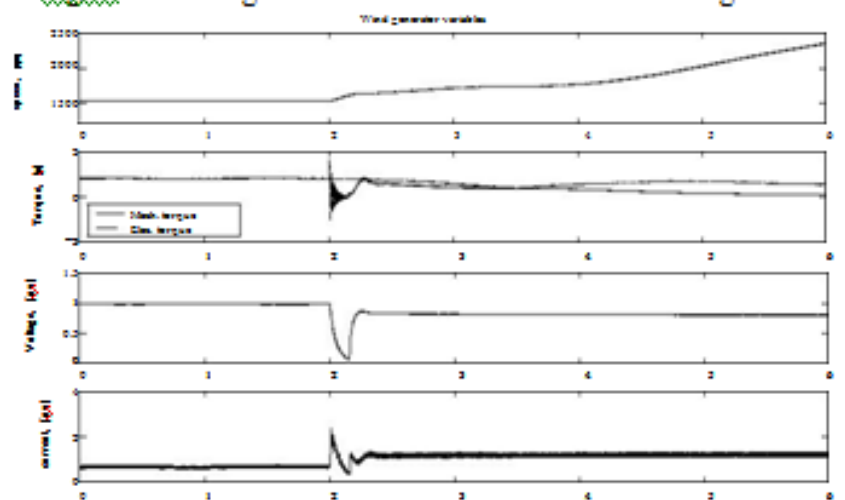

Fig. 5. Simulation results with pitch control but without STATCOM. 


\section{International Journal of Science and Research (IJSR) \\ ISSN (Online): 2319-7064}

Index Copernicus Value (2013): 6.14 | Impact Factor (2014): 5.611

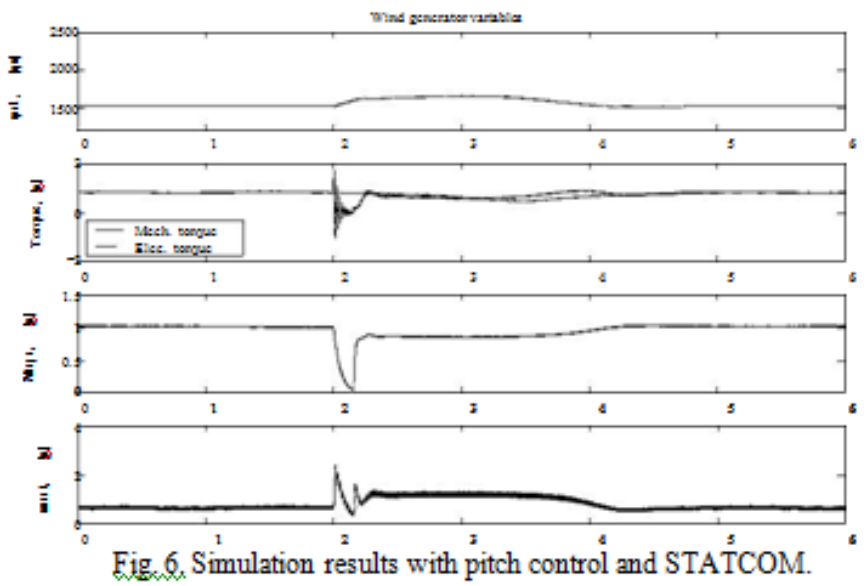

A three-phase short-circuit fault occurs on the middle of one of the two parallel lines. It begins at $2 \mathrm{~s}$ and the line is tripped after $150 \mathrm{~ms}$. The voltage at the wind turbine drops during the fault period, which leads to a reduction in the electromagnetic torque and acceleration of the rotor. The pitch angle control is in emergency operation to limit the input power during the power system fault. The results with and without the STATCOM in operation are respectively presented in Fig. 5 and Fig. 6. In Fig. 5, it can be clearly seen that the generator terminal voltage can not recovered after the fault and the generator will be tripped by the overspeed protection. In Fig. 6, the STATCOM effectively restored the generator terminal voltage and the system will restore normal operation. It can be seen that the STATCOM control is an effective way to improve system stability in this case.

\section{Conclusion}

As it requires to cancel out reactive and harmonic parts of loud current and also to maintain the source voltage and current in phase at the point of common coupling in the grid system, this paper serves its motive to suggest the scheme for maintaining power quality in such a required manner. Integration of large scale wind power into power systems present many new challenges. This paper presents the impacts of wind power on power quality, the gird requirements for integration of wind turbines, and discusses the potential operation and control methods to meet the challenges.

\section{References}

[1] Tande, J.O.Q., Applying power quality characteristic of wind turbine for assessing impact on voltage quality Wind Energy, pp. 5, 37-2002

[2] Thiringer, T. Petrup P. „Power Quality Impact of Sea Located Hybrid Wind Parke IEEE Tran. on Energy Conversion, pp. 23-127, 2001.

[3] Z. Chen, E. Spooner, ,Grid Power Quality with Variable Speed Wind Turbinese, IEEE Trans on Energy Conversion, Vol. 16, No .2, pp. 148-154, June 2001.

[4] Z.Chang, E. Spooner," Grid power quality with variable speed wind turbine", IEEE Trans. on Energy Conversion, Vol. 16, No. 2, June 2003.

[5] Sung-Hun, Seong R. Lee, Hooman Dehbonei, Chemmangot V. Nayar," Application of Voltage-and
Current-Controlled Voltage Source Inverters for Distributed Generation System.," IEEE Trans. On Energy Conversion, Vol.21, No.3, pp. 782-788, Sept. 2006

[6] S.W. Mohod, M.V. Aware, "Grid Power Quality with Variable Speed Wind Energy Conversion."proceeding of IEEE Int. Conf. on Power Electronic Drives and Energy System (PEDES), Delhi, 5A-21, Dec. 2006.

[7] S.W. Mohod and M.V. Aware, "A STATCOM control scheme for grid connected wind energy system for power quality improvement," IEEE, System Journal, Vol. 2, issue 3, pp. 346-352, Sept. 2010.

[8] Chong Han, Alex Q. Huang, Mesut Baran, Subhashish Bhattacharya, Wayne Litzenberger, Loren Anderson, "STATCOM Impact Study on the Integration of a Large Wind Farm into a Weak Loop Power System.", IEEE Trans. On Energy Conv., Vol. 23, No. 1, March 2008, pp. 226-232.

[9] P. Siemes, H.J. Haubrich, H. Vennegeerts, „Concepts for the improved integration of wind power into German interconnection System"e, IET Review, Vol. 2, No.1, pp. 26-33, Power generation 2008.

[10] A.Sannino, "Global power systems IEEE General Meetingfor,Denver,sustainableCO,Jun.2004. development,"

[11] K. S. Hook, Y.Liu, and S. Atcitty,"Mitigation of the wind generation EPQU integration $J$., vol. XII,no. rela2, 2006.

[12]A.E. Hammad, Comparing the Voltage source capability of Present and future Var Compensation Techniques in Transmission System, IEEE Trans, on Power Delivery. Volume 1. No.1 Jan 1995.

[13]Haque, M.H., "Compensation of Distribution TATCOM",PowerTechProceedings, Systems 2001IEEE VoltagePorto,Volume sags b 1, PP.10-13, September 2001.

[14] Anaya-Lara O, Acha E., "Modeling and AnalysisIEEE OfTransactionsCustomonPower Delivery, PowerVolumeSystems 17, Issue: 2002, Pages: 266-272.

[15]Bollen, M.H.J.,"Voltage sagsngReview,in IEEE,ThreeVolume2 1,PhaseIssue:9, SeptemberSystems" ,2001,PP:11-15. Power Engin

[16] K.Malarvizhi and K.Baskaran,"in FixedEnhancemSpeentd Wind of VoltaEnergey StabilityConversion 